\title{
Platão e a Crítica da Poesia
}

Adriana Natrielli (Bolsista PIBIC/CNPq - DF/USP/SP)

Orientador: Luis Fernando Franklin de Matos

Pretendo tratar, aqui, do prefácio ao livro Platão e a Arte de seu Tempo de P. M. Schuhl, intitulado PLATÃO CRÍTICO DE ARTE. Este prefácio foi uma comunicação apresentada em 1936 por Schuhl num congresso internacional de história da arte em Berna. O ponto de partida adotado por Schuhl foi uma outra comunicação feita por Gustave Fuguér, treze anos antes, sobre Sócrates crítico de arte. Este título, por sua vez, justifica-se por uma passagem dos Memoráveis, livro III capítulo X, na qual Xenofonte nos mostra Sócrates conversando com o pintor Parrásio sobre a maneira de se representar a alma dos modelos.Sócrates vai lhe fazer a seguinte indagação:

-- Diz-me Parrásio, não é a pintura representação das coisas visíveis ? - Assim é

- E se quiserdes representar formas de beleza perfeita... como não é fácil encontrar homem isento de imperfeição... não irás reunir vários modelos e de cada um tomarás o que de mais formoso possuir compondo um todo de perfeita beleza ? É o que fazemos.

-- E aquilo que mais atrai enleva e seduz : a expressão moral da alma, não a imitais também ? Ou será inimitável ?

- Como imitá-la, oh Sócrates, se não tem proporção, nem cor, nem nenhum atributo de algo que seja visível ?

- O que?! Não se nota nos olhos ora afeição, ora ódio ora alegria, ora tristeza? -- Nota-se.

- Então não há como retratar essas expressões nos olhos ? - Há.

- Então, não se pode também representar os afetos do ânimo ?

-- Indubitavelmente -- disse Parrásio.

É claro que Platão não representou, como Xenofonte, o pintor ou o escultor às voltas com Sócrates, mas em seus diálogos vemos que as alusões as artes são por demais numerosas. Como podemos notar, desde Sócrates aparecem os problemas da mimese, da separação entre o mundo sensível e o mundo das idéias, presente em Platão, e do homem como objeto da arte. Embora Sócrates não se refira diretamente a práxis humana como faz Aristóteles, considera que a arte pode imitar não só as coisas visíveis como também as expressões da alma, as emoções e os sentimentos humanos.

Mas Schuhl nos propõe a seguinte pergunta: Não seria paradoxal falar em Platão crítico de arte, quando nos lembramos o quanto ele foi severo em seus diálogos com os artistas, amadores e com os próprios críticos de arte? Pode até ser.

Seria paradoxal porque esperamos que um crítico de arte, pelo menos, goste de arte e não queira afastar-se dela ou expulsar quase todos os artistas de uma cidade que ele considera ideal. Mas, como veremos as coisas não são bem assim 
para Schuhl, ele irá se esforçar no decorrer do texto tentando defender Platão.

Realmente, sabemos o quanto Platão é desconfiado em relação aos artistas, o que revela na maioria das vezes até um preconceito. Sabemos também o quanto ele é inflexível e do caráter dogmático de suas teses. Acontece que para Platão a verdade deve estar acima de tudo, deve ser uma só e, principalmente, quando se discute questões morais, não há espaço para opiniões. Portanto a finalidade dos diálogos é chegar à verdade sobre os fatos e pronto.

Para ilustrar essa inflexibilidade, Schuhl cita um trecho do Fédon no qual Sócrates volta a expor sua doutrina sobre as idéias:

"Se alguém me diz por que razão um objeto é belo, e afirma que é porque tem cor e forma, ou devido qualquer coisa desse gênero; afasto-me sem discutir, pois todos esse argumentos causam-me unicamente perturbação. Quanto a mim, estou firmemente convencido, de um modo simples e natural, talvez até ingênuo, que o que faz belo um objeto é a existência daquele belo em si, de qualquer modo que se faça a sua comunicação com ele."

Continuando, Schuhl descarta a possibilidade de pensarmos que Platão pudesse ter algum defeito de sensibilidade à arte. Por que poderíamos pensar isso? Provavelmente porque Platão, tendo em vista algo que fosse assim tão perfeitamente belo, veria as demais coisas que são belas perderem o brilho por nunca poderem igualar-se àquilo que é o belo em si. Schuhl descarta essa possibilidade na medida em que considera a própria obra de Platão, enquanto literária, possuidora de uma intensa beleza. Vou ler o trecho em que Schuhl faz a apreciação da obra de Platão:

"Platão mostra-se em toda sua obra um artista demasiadamente genial para que essa atitude (que, como já dissemos, de austeridade em relação aos artistas) pudesse se explicar por um defeito de sensibilidade à arte. Sua prosa é luminosa a maneira da riqueza e transparência dos tecidos finos que os escultores de seu tempo aplicaram aos corpos de Vitória de Pargos e Athena Nikê; como no Fedro quando Platão narra o rapto de Orithe por Dorê".

Além de considerar essa sensibilidade, Schuhl nota que o próprio Platão reconhece o charme quase mágico da poesia imitativa e, nota ainda, que mesmo se Platão tomar a decisão de afastar-se da arte, por não considerá-la de algum modo proveitosa, isso será sempre muito penoso, justamente por esse seu amor a ela. Mas como a razão deve sempre falar mais alto que a paixão este afastamento se faz necessário. Vou citar o trecho do livro $X$ da República ao qual Schuhl se refere:

"Mesmo assim, diga-se que, se a poesia imitativa voltada para o prazer tiver argumentos para provar que deve estar presente numa cidade bem governada, a receberemos com gosto, pois temos consciência do encantamento que sobre nós exerce; mas seria impiedade trair o que julgamos ser verdadeiro." 2

"Mas se assim não for, meu caro amigo, faremos como aqueles que, quando estão apaixonados por alguém, e reconhecem que aquele amor não lhes é proveitoso, se afastam dele embora com esforço; do mesmo modo nós, devido ao amor por essa poesia que em nós se formou por influência da educação de nossos belos estados, estaremos disposto a vê-la como muito boa e verdadeira, mas, enquanto não for capaz de se justificar, escutá-la-emos, repetindo para nós mesmos os argumentos que expusemos, e aquele mesmo canto mágico, tomando 
precauções para não cairmos novamente naquela paixão da nossa infância, e que é a da maioria."

Para completar esta defesa da sensibilidade artística, a despeito de toda atitude severa com os artistas, Schuhl evoca uma passagem do Político, na qual para ele, Platão deixa escapar a voz do coração. É quando o estrangeiro propõe ao jovem Sócrates, uma situação na qual a arte estaria completamente condenada:

"Além de tudo isso seria necessário ainda elaborar a seguinte leei: quem quer que procurasse estudar uma profissão, fora das leis escritas não poderia em primeiro lugar ser chamado de médico ou piloto e sim, visionário e sofista fraseador: em seguida, o primeiro que tivesse esse direito acusa-lo ia diante de um tribunal (...). Pois não temos o direito de sermos mais sábios que as leis nem de ignorar [a medicina, a higiene, a arte náutica e a navegação], sendo permitido a quem quiser, aprender os preceitos escritos e os costumes tradicionais. Se as ciências, caro Sócrates, fossem tratadas da maneira porque descrevemos, se fossem reguladas por um código (...) o que aconteceria a tudo isso, conduzido pela sorte, regido pela letra escrita em lugar de orientado pela arte?

- É claro que veríamos desaparecer completamente todas as artes, sem esperança nenhuma de retorno, sufocadas por essa lei que proíbe toda pesquisa. E a vida que já é bastante penosa tornar-se-ia então totalmente insuportável."4

Schuhl nos propõe agora a seguinte questão: Reprovar o espectador por ele não saber se elevar até a Idéia do Belo, não é admitir implicitamente a possibilidade de uma crítica de arte fundada na filosofia e constituída, por ela mesma, uma propedêutica à intelecção da obra de arte? De fato este tem sido o ponto de vista de um certo número de críticos que se reclamam da tradição platônica. E nos propõe ainda uma segunda questão:

Não seria a Idéia, a estrutura ordenada que faz a excelência e a beleza de todos os seres e coisas, neste ponto, a mesma que os pintores e os bons oradores, como todos os artistas, sabem dar as suas obras? Esta ordem e beleza em si mesmas, ou seja, como considera Platão, as idéias puras que temos destas coisas, de alguma forma encontram-se nas obras dos artistas e o verdadeiro artista seria aquele que consegue chegar, por trás das aparências, à essência ideal, à realidade profunda das coisas; e, na perspectiva acima mencionada de uma crítica de arte fundada na filosofia, o papel do crítico seria o de estudar como o artista exprime suas idéias ajudando assim o público a percebê-la na obra.

"Ora bem! Parece-te que há alguma diferença entre os cegos e aqueles que estão verdadeiramente privados do conhecimento de todo ser, e que não tem na alma nenhum modelo claro, nem são capazes de olhar, como pintores. para a verdade absoluta, tomando-a sempre como ponto de referência, e contemplando-a com o maior rigor possível, para só então promulgar leis cá na terra sobre o belo, o justo, o bom, se for o caso disso, e preservar as que existirem, mantendo-as a salvo?"5

Isso leva Platão a dar valor ao pintor que sabe desenhar um tipo de homem o mais belo possível, mesmo sem poder mostrar que existe um modelo correspondente na realidade. A final, não é essa a tarefa a que Platão se propõe quando constrói na imaginação uma cidade ideal? Citarei um trecho da República que se encontra no livro V: 
Julgas então que um pintor vale menos, se tiver desenhado um modelo do que seria o mais belo dos homens, e transmitido suficientemente à sua pintura todas as qualidades, mas não puder demonstrar a possibilidade da existência de um homem desses? (...) E então? E nós também, não estivemos a fazer com nossas palavras o modelo de uma cidade boa? (...) Julgas então que falamos menos bem, se não pudermos demonstrar que é possivel fundar uma cidade tal como a que dissemos? - Sem dúvida que não."

Entretanto, Schuhl observa que não há nada mais antiplatônico que confundir a Imagem com a Idéia. E o ideal no qual se inspiram os artistas oscila entre os dois. Mas, a obra do artista, está mais afastada das idéias que os objetos sensíveis como nos mostra aquela célebre passagem da República que fala sobre os três tipos de cama: a cama do artista é uma imitação da cama do marceneiro que por sua vez é uma imitação da cama ideal. ${ }^{7}$

Schuhl comenta um artigo de Edmond Porttier ${ }^{8}$, o qual interpreta que certas incorreções em desenhos ilustrativos de vasos se explicam pelo fato de que os decoradores e mesmo os pintores traçaram por muito tempo suas figuras utilizando silhuetas obtidas a partir da projeção da sombra dos objetos representados. A existência desse procedimento, que foi empregado sobretudo no séc. VI a.C., mas que Platão no entanto pode conhecer, mesmo se ele não o viu mais sendo praticado, é suscetível de nos ajudar a compreender melhor a atitude adotada na observação das artes imitativas e na alegoria da caverna ${ }^{9}$ Os pintores, fizeram outra coisa, senão decorar a parede tentando fixar o desfile de sombras fugitivas que se sucediam?

Schuhl completa seu raciocínio com a idéia de que há ainda outras razões para se explicar a severidade de Platão: em primeiro lugar, sem dúvida, que a arte não pode viver sem se transformar. A coisa é particularmente sensível em um tempo no qual o gosto se modifica, quando tudo se dissolve e se renova, tanto no domínio estético quanto no domínio político: uma revolução está em curso e seu término ainda não foi alcançado. Ora, a mudança (que, para Platão, se confunde quase sempre com a decadência) Ihe parece ainda mais perigosa que na medicina hipocrática a mudança do regime habitual

Ainda nos diz que, segundo Dâmon ${ }^{10}$, não se pode modificar os modos musicais sem abalar a constituição do Estado:

"Portanto, resumindo em poucas palavras devem os encarregados da cidade apegar-se a este sistema de educação, a fim de que não thes passe despercebida qualquer alteração, mas que a tenham sob vigilância em todas as situações, para que não haja inovações contra as regras estabelecidas na ginástica nem na música. Acautelem-se o mais possível, com o receio de, se alguém disser que 'os homens apreciam acima de tudo o canto que tiver mais novidade'11 se julgar talvez que - poeta quer referir-se não a cantos novos, mas a uma nona maneira de cantar, e que a elogia. Tal coisa não deve louvar-se nem entender-se assim, porquanto devese ter o cuidado da mudança para um novo gênero musical, que pode pôr tudo em risco. É que nunca se abalam os gêneros musicais ${ }^{12}$ sem abalar as mais altas leis da cidade, como Dâmon afirma e eu creio"13

Do mesmo modo, continua Schuhl, Platão reprova certa procura por novos prazeres como acontece em todo lugar salvo, diz ele, no Egito, em Creta e Esparta, e, 
assim, se mostra partidário de uma arte imutável e hierática, ou seja, que aplica-se às formas tradicionais que a religião impõe às obras de arte, tal como as que ele teria admirado nos templos do vale do Nilo: os objetos pintados ou modelados eram feitos seguindo as mesmas regras há dez mil anos, e das quais eles estariam impedidos de se desviar.

Partindo do ponto de vista, no qual Platão seria totalmente favorável a uma arte arcaizante como esta, Schuhl supõe que neste contexto o crítico de arte se veria desobrigado do estudo das obras primas antigas, bastaria a analise das regras a que eles foram levados a respeitar. De fato, sofistas e técnicos acabaram por se reduzir à teoria, e por submeter à regras a prática de todas as artes da retórica à culinária ${ }^{14}$; Policleto teria ensinado em seu tratado, o Canon, as proporções relativas às partes dos corpos.

Portanto, se Platão foi totalmente favorável às leis que impediam os artistas egípcios "de inovar nem de imaginar nada que não estivesse conforme à tradição ancestral" como diz ele nas Leis, isso se dá devido à tomada de consciência do perigo que representa para a arte uma tal imitação. E, ainda, apesar de ter dito no Político, como vimos no início, que "Se o artista devesse sempre se conformar às regras escritas, codificadas pelos tratados, se uma tal lei lhe impedisse de pesquisar, as artes se perderiam totalmente por não poderem nunca se renovar" os argumentos opostos são os que vencem no final das contas.

Schuhl passa a observar que estava em desenvolvimento naquela época, sob influência da pintura de cenários, uma espécie de impressionismo ilusionista que visava o tromp-l'oeil (os olhos, dizia Plínio, viam percorrer até o palco as uvas pintadas por Zêuxis!), impressionismo no qual Platão reprovava pela afinidade com a sofística, e a influência que ela exerce sobre as partes da alma mais fáceis de se abalar; sobre o sentimento, sobre todos os elementos irracionais. À estética da ilusão preconizada por Górgias, Platão opõe a estética da imitação; ele se mostra sobretudo hostil à crítica que toma como critério a reação do público.

Após a crítica de Platão aos críticos, Schuhl passa a comentar a crítica platônica aos próprios artistas participantes daquele impressionismo ilusionista, ou seja, dirigida aos pintores e escultores que deformam suas obras para obterem a perspectiva. Em certa altura do diálogo Sofista, quando o estrangeiro distingue na mimética a arte da cópia, estabelecendo que aquele que copia mais fielmente transporta as relações exatas entre as medidas, diz que, no entanto, não são todos que imitam de maneira a reproduzir exatamente as proporções do modelo :

"Menos aqueles, pelo menos, que devem modelar ou pintar uma obra de grandes dimensões. Se, na realidade reproduzissem estas maravilhas em suas verdadeiras proporções, sabes que as partes posteriores nos apareceriam exageradamente pequenas e as partes superiores, muito grandes, pois, a umas vemos de perto e, a outras, de longe.

Por fim Schuhl volta a argumentar de maneira a dar a Platão a oportunidade de corrigir o rigor de seus pontos de vista. Primeiro, pelo fato de que uma cópia perfeita não seria uma imagem mas uma duplicata como vemos numa passagem do Crátilo:

"Se um deus artista reproduzisse não somente a cor e a forma de Crátilo, mas sua alma e seu pensamento, não teríamos mais adiante de nós Crátilo e sua imagem, mas dois Crátilos" 
1937, p. 262-295.

9. Ver o ensaio intitulado "Autor de la Caver ne" in Études sur la fabulation platonicienne, p. 45-74.

10. Conforme supra, n. 63 ao livro III da República: Dâmon foi um célebre mestre de música ateniense do séc. $V$ a.C., que ocupou-se especialmente das relações entre a ética e a música.

11. Odisséia I. 351-352

12. Conforme supra, $\mathrm{n} .7$ ao livro IV da República : discute-se se os trópoi musicais de que se fala no texto seriam, como no tempo de Aristides Quintiliano, as três espécies de composição (nômica ditirâmbica e trágica) ou se tal divisão não estaria ainda estabelecida. A conotação ética dos gêneros musicais entre os Gregos, está amplamente documentada em textos do próprio Platão, bem como em outros autores antigos.

13. A República, IV 424 bc

14. ver, do mesmo autor, Formation de la pensée grecque, p. 343 